\title{
RESEARCHPAPER
}

\section{Isolation of ureolytic bacteria from different sources and their characterization}

\author{
URMILA GUPTA PHUTELA ${ }^{1}$ AND MANISHA PARMAR ${ }^{2}$ \\ ${ }^{1}$ School of Energy Studies for Agriculture, College of Agricultural Engineering and Technology, Punjab Agricultural \\ University, LUDHIANA (PUNJAB) INDIA \\ ${ }^{2}$ Department of Microbiology, College of Basic Sciences and Humanities, Punjab Agricultural University, \\ LUDHIANA (PUNJAB) INDIA (Email : manishaparmar1031@gmail.com) \\ Email : phutelau@gmail.com
}

Received : 18.11.2016; Revised : 12.03.2017; Accepted : 23.03.2017

The present study was aimed at isolation and characterization of urease producing bacterial strains for improving the strength of cement concrete. A total of 1500 colonies were isolated from different samples like cowshed, poultry farm, milk, soil and pigeon dung. These isolated cultures were purified on phenol red agar plates. Out of total, 17 bacterial cultures showed pink coloured colonies indicating the presence of urease enzyme. These isolates were characterised on the basis of Gram's staining, size, shape, colour (also known as pigmentation), texture and elevation, ability to form endospores, catalase test, hydrogen sulphide production and acid production and carbohydrate utilization test.

Key words : Urease, Calcium carbonate precipitation, Characterization, Endospore

How to cite this paper : Phutela, Urmila Gupta and Parmar, Manisha (2017). Isolation of ureolytic bacteria from different sources and their characterization. Asian J. Bio. Sci., 12 (1) : 21-25.DOI : 10.15740/HAS/AJBS/12.1/21-25. 